\title{
Avaliação de Herbicidas Aplicados em Pós-Emergência sobre e sob a Palha em Cana Crua e o Destino ambiental ${ }^{1}$
}

\author{
Evaluation of Herbicides Applied in Post-Emergence over and under Straw in No-Burn \\ Sugarcane and their Environmental Fate
}

FOLONI, L.L. ${ }^{2}$, PLESE, L.P.M. ${ }^{3}$, SILVA, C.L. ${ }^{4}$ e FILHO, J.T. ${ }^{5}$

\begin{abstract}
RESUMO - O objetivo deste trabalho foi avaliar a eficiência de vários herbicidas isolados ou associados, aplicados em pós-emergência, na cultura da cana-soca, colhida mecanicamente no sistema cana crua, procurando evidenciar diferenças no seu desempenho quando aplicados sobre ou sob a palha, bem como, ainda dentro do conceito de sustentabilidade e avaliação de risco ambiental, quantificar os comportamentos nos quais esses produtos apresentam maior risco. O experimento foi conduzido no município de Bariri-SP, em áreas da Usina Della Colletta, Fazenda Santo Antonio, em área de cana-soca (cultivar RB 72 754) colhida mecanicamente. Foi utilizada a cana-soca de quarto corte, plantada no espaçamento de 1,40 m, em solo Argiloso Vermelho-Amarelo com 5\% de declive. Empregou-se o delineamento experimental de blocos ao acaso com 14 tratamentos (trifloxysulfuron-sodium+ametrina 720 e 960; mesotrione 182 e 292,6; mesotrione+ametrina 292,6+1.500; mesotrione+trifloxysulfuronsodium 182,8+720; metribuzin 2.680; trifloxysulfuron-sodium+ametrina + hexazinone+diuron 720+900; amicarbazone 45; hexazinone+diuron 1.320; trifloxysulfuron-sodium+sulfentrazone $720+700$ (todos em gramas de ingrediente ativo); testemunha; testemunha capinada) e quatro repetições, para cada tipo de aplicação (sobre e sob a palha) disposta lado a lado. As avaliações realizadas foram: fitotoxicidade aparente, altura, estande, eficiência no controle da Digitaria horizontalis, Cenchrus echinatus, Emilia fosbergii e Sida cordifolia, números de internódios e o primeiro internódio. O modelo matemático foi o nivel I de fugacidade, utilizando os compartimentos ar, água, solo, sedimento, biota, raiz, caule e folha. Os resultados mostraram que os herbicidas trifloxysulfuron + diuron, mesotrione, metribuzin, ametrina, hexazinone + diuron, amicarbazone e sulfentrazone isolados ou associados, aplicados em pós-emergência, em área total da cultura da cana-de-açúcar, foram altamente eficientes no controle das principais plantas daninhas presentes. A aplicação desses herbicidas sobre ou sob a palhada da cana crua não mostrou diferença na eficiência de controle ou sobre os demais parâmetros avaliados. A aplicação do modelo de fugacidade objetivando avaliar o comportamento preferencial mostrou que todos os herbicidas tendem a ter maior distribuição no compartimento água.
\end{abstract}

Palavras-chave: avaliação ambiental, eficiência, fugacidade, planta daninha, pesticidas, Saccarum officinarum.

\begin{abstract}
This study aimed to evaluate the efficiency of several herbicides, applied alone or mixed in post-emergence on ratoon sugarcane crop, mechanically harvested under a no-burn system, to assess differences in performance when applied over or under the straw. In addition, based on the concept of sustainability and environmental risk evaluation, mathematical models were used to evaluate the fate of these herbicides. The experiment was carried out in the municipality of Bariri-SP, in the Della Colletta Processing Plant section of Santo Antonio Farm's sugarcane (RB 72754 cultivar) cultivated areas. Ratoon sugarcane was planted with $1.40 \mathrm{~m}$ spacing on Red-Yellow Argisol soils with 5\% declivity. The experiment was arranged in a randomized block design in 14 plots
\end{abstract}

Recebido para publicação em 20.11.2009 e na forma revisada em 6.5.2011.

2 Professor colaborador do Curso de Pós-Graduação, Faculdade de Engenharia Agrícola, Universidade Estadual de Campinas UNICAMP, <lfoloni@gmail.com>; 3 Professor, Dr., Instituto Federal de Educação, Ciência e Tecnologia do Acre, IFAC; <pedro.plese@ifac.edu.br>; ${ }^{4}$ Aluno de Pós-Graduação, Faculdade de Engenharia Agrícola, UNICAMP, ${ }^{5}$ Professor, Dr., Faculdade Estadual de Engenharia Agrícola, UNICAMP.

Planta Daninha, Viçosa-MG, v. 29, n. 2, p. 447-455, 2011 
(trifloxulfurom-sodium+ametryn 720 and 960; mesotrione 192 and 292.6; mesotrione and ametryn 292.6+1500; mesotrione+trifloxysulfuron-sodium 182.8+720; metribuzin 2680; trifloxysulfuronsodium+ametryn thexazinone+diuron 720+900; amicarbazine 45; hexazinone+diuron 1320; trifloxysulfuron-sodium+sulfentrazone 720+700 (all of the above cited in grams of active ingredients)); control; weeded control, and four replicates, for each type of application (over or under the straw), side by side. The following evaluations were carried out: phytotoxicity, height, stand, efficiency of control of Digitaria horizontalis, Cenchrus echinatus, Emilia fosbergii and Sida cordifolia, number of stalks and first stalk. A fugacity-level I mathematical model was used including the following compartments: air, water, soil, sediment, biota, strain, leaves and roots. The results showed that the herbicides trifloxysulfuron+diuron, mesotrione, metribuzin, ametryn, hexazinone+diuron, amicarbazone and sulfentrazone, alone orin combination, applied in post-emergence on sugarcane were highly efficient in controlling the major weeds present. Application of these herbicides over or under no burn sugarcane straw did not show differences of control efficiency nor of any other parameter. Application of the fugacity model aimed at evaluating preferential behavior showed that all the herbicides tended to have greater distribution in the water compartment.

Keywords: environmental evaluation, efficiency, fugacity, weed, pesticides, Saccharum officinarum.

\section{INTRODUÇÃO}

No sistema mecanizado da colheita da cana-crua, a quantidade de palha que sobra no solo é dependente da variedade plantada. EsSe resto de cultura (palha) faz com que as propriedades físicas, químicas e biológicas do solo se modifiquem, bem como a presença e o desenvolvimento fisiológico das plantas daninhas. Fatores como a umidade e temperatura do solo e efeitos alelopáticos podem interferir no processo de desenvolvimento dessas plantas.

Para controle das plantas daninhas no sistema de cana-crua, a palha se torna um obstáculo positivo na diminuição do banco de sementes, porém tem seu lado negativo para aplicação de herbicidas, pois pode prejudicar eficiência do contato com a planta-alvo (Monquero et al., 2007, 2009a,b; Ferreira et al. 2010). Estudos têm sido realizados para melhorar a aplicação de herbicida no controle, como o proposto por Velini \& Negrisoli (2000), que instalaram um pulverizador na colheitadeira para que a aplicação ocorresse após o corte e antes de a palha atingir o solo.

Além disso, uma série de trabalhos desenvolvidos por Azania et al. (2006), Simoni et al. (2006), Monquero et al. (2007, 2009b) e Negrisoli et al. $(2007 a, b)$ sobre a eficácia de herbicidas em presença ou não da palha na superficie mostram que esses produtos respondem de forma diferenciada no desempenho do controle de plantas daninhas. $\mathrm{Na}$ aplicação sobre palha, estudos recentes têm demonstrado que a precipitação se torna um meio pelo qual o herbicida retido na palha atinge o solo pelo processo de lixiviação (Simoni et al., 2006; Cavenaghi et al., 2007; Negrisoli et al., 2007a,b; e Toledo et al., 2009), podendo assim ser absorvido pela planta daninha e, consequentemente, melhorando a eficácia do produto no controle desta.

No desenvolvimento da cana-de-açúcar, a palha pode prejudicar inicialmente o crescimento como também causar problema de fitotoxicidade à cultura devido à presença de resíduo do herbicida nela aplicado (Martini \& Durigan, 2004; Ferreira et al., 2005). Com isso, a planta daninha pode germinar juntamente com a cultura e competir por luz, nutrientes e umidade. Todos esses fatores podem gerar perda de produtividade.

Por outro lado, a palha pode influenciar o comportamento e destino ambiental do herbicida no solo, pois o resíduo nela presente pode se espalhar para vários outros compartimentos ambientais por processos de transporte, provocando com isso uma série de consequências a saúde humana, à flora e à fauna do meio.

Por isso, a questão do desenvolvimento sustentável de qualquer atividade agrícola não deve ser negligenciada. No Brasil, a questão da avaliação do impacto ambiental quando da utilização de produtos fitossanitários é recente e são escassos os estudos referentes ao tema. 
Esse assunto começou a ter importância após a publicação da Lei 7802 de junho de 1989.

Uma forma possivel de predição dos destinos consiste na utilização de modelos matemáticos, que, com uma série de dados e modelos ajustados, procuram determinar como e quais compartimentos podem ser afetados. Embora o conceito de fugacidade não seja novo, no Brasil apenas alguns estudos teóricos e raras pesquisas de campo avaliam essa propriedade, principalmente para o comportamento de produtos fitossanitários no meio ambiente. A fugacidade pode ser um novo caminho e, talvez, o melhor meio de quantificar o transporte, a bioacumulação e a transferência entre os compartimentos, conforme pode ser observado nos trabalhos de Paraíba et al. (2007), Silva et al. (2007) e Plese et al. (2008). Essa ferramenta pode ser de grande valia para os estudos de impacto ambiental na utilização de produtos fitossanitários na cultura da cana-de-açúcar

O objetivo deste trabalho foi avaliar a eficiência de vários herbicidas isolados ou associados, aplicados em pós-emergência, na cultura da cana-soca colhida mecanicamente no sistema cana-crua, procurando evidenciar diferenças no seu desempenho quando aplicados sobre ou sob a palha, bem como, ainda dentro do conceito de sustentabilidade e avaliação de risco ambiental, quantificar os comportamentos nos quais esses produtos apresentam maior risco.

\section{MATERIAL E MÉTODOS}

O experimento foi conduzido no municipio de Bariri-SP, em áreas da Usina Della Colletta, Fazenda Santo Antonio (coordenadas $21^{\circ} 59^{\prime} 18^{\prime \prime} \mathrm{S}$ e 4843'35" WGR), em área de canasoca colhida mecanicamente em dezembro de 2006. A cultura da cana-de-açúcar, cultivar RB 72 754, foi implantada em março de 2002, sendo cana-soca de quarto corte, plantada no espaçamento de $1,40 \mathrm{~m}$, em solo arenoso Vermelho-Amarelo com 5\% de declive. Foi empregado o delineamento experimental de blocos ao acaso com 14 tratamentos e 4 repetições, compreendendo cada parcela uma área de 4,0 x 5,0 m, perfazendo 20,0 $\mathrm{m}^{2}$ de área tratada para cada tipo de aplicação (sobre e sob a palha), disposta lado a lado. Antes da aplicação dos herbicidas, a parcela na qual este seria aplicado sob a palha foi retirada manualmente e, após a aplicação, reposta na mesma posição e quantidade, de forma que representasse assim a aplicação em solo limpo. Os dados médios de controle (\%) foram comparados estatisticamente pelos testes de Tukey a 5\% e F. Os tratamentos e as respectivas doses encontram-se na Tabela 1.

Os tratamentos herbicidas foram efetuados 65 dias após o último corte, com a cultura no estádio vegetativo, entre 60 e $80 \mathrm{~cm}$ (última lígula visível) sem a formação de colmos, com cinco a seis folhas. O complexo florístico por ocasião da aplicação era composto de Digitaria horizontalis (15 plantas $\mathrm{m}^{-2}$ ), Cenchrus echinatus (10 plantas $\left.\mathrm{m}^{-2}\right)$, Emilia fosbergii $\left(5\right.$ plantas $\left.\mathrm{m}^{-2}\right)$ e Sida cordifolia (10 plantas $\mathrm{m}^{-2}$ ).

Os tratamentos herbicidas foram pulverizados em 10 de fevereiro de 2007 em área total da parcela, empregando equipamento de precisão a gás carbônico $\left(\mathrm{CO}_{2}\right)$ da marca R\&D Sprayers, provido de barra compensada, contendo quatro bicos de jato plano marca TeeJet XR 110,02, espaçados entre si de $0,50 \mathrm{~m}$, promovendo 2,0 $\mathrm{m}$ de largura efetiva.

O equipamento foi operado a $278 \mathrm{kPa}$ $\left(2,78 \mathrm{kgf} \mathrm{cm}^{-2}\right.$ ou 40,0 psi), empregando água como diluente e volume de aplicação de $150 \mathrm{~L} \mathrm{ha}^{-1}$. As condições ambientais verificadas por ocasião da aplicação foram: temperaturas do ar de $31,7{ }^{\circ} \mathrm{C}$ a $34,3{ }^{\circ} \mathrm{C}$; umidade do ar entre 76 e $61 \%$; velocidade do vento entre 3 e $6 \mathrm{~km} \mathrm{~h}^{-1}$, com direção predominante sudoeste e cobertura do céu em $80 \%$; e solo úmido. Nas parcelas onde os herbicidas teriam de ser aplicados sob a palha, esta foi retirada manualmente e, após aplicação, retornada sobre a área na mesma proporção.

Foram efetuadas avaliações de seletividade (fitotoxicidade aparente, utilizando a escala EWRC (1984) e eficiência agronômica, de forma visual aos 15, 30 e 60 dias após tratamento - DAT), empregando a escala percentual, em que zero $(0 \%)$ representa nenhum controle e cem (100\%) o controle total, comparado à testemunha sem capina (SBCPD, 1995). Foi realizada ainda a biometria na avaliação final, correspondendo ao desenvolvimento da cultura (altura da última lígula visivel do solo até o ápice - em $\mathrm{cm}$ ), estande (contagem do número de perfilhos por metro 
linear) e medida do diâmetro médio do primeiro internódio (medido na parte mediana com paquímetro Mytutoyo, com escala de $0,1 \mathrm{~cm})$.

Para aplicação do modelo de fugacidade nível I (Mackay, 1991) foi utilizado as características físico-químicas dos herbicidas (Tomlin, 2001; Rodrigues \& Almeida, 2005) para determinar a distribuição ambiental dos mesmos. Os compartimentos estudados foram: ar, água, solo, sedimento, biota, raiz, folha e caule. Os parâmetros determinados no modelo de fugacidade nivel I (Mackay, 1991) para os compartimentos utilizados no cálculo foram: volume $\left(\mathrm{m}^{3}\right)$; densidade $\left(\mathrm{kg} \mathrm{m}^{3}\right)$; a fração de carbono orgânico (\%). Foram calculados fugacidade $(\mathrm{Pa})$, concentração $\left(\mathrm{g} \mathrm{m}^{-3}\right)$, capacidade de fugacidade $\left(\mathrm{mol} \mathrm{m}^{-3} \mathrm{~Pa}^{-1}\right)$ e a quantidade do herbicida em cada compartimento (\%) (Mackay \& Paterson, 1981; Calamari et al., 1987; Mackay, 1991).

Tabela 1 - Herbicidas testados e doses aplicadas, em ingrediente ativo (i.a.) e produto comercial por hectare, respectivamente

\begin{tabular}{|l|c|c|c|}
\hline \multicolumn{2}{|c|}{ Nome } & \multicolumn{2}{c|}{ Dose por ha } \\
\hline Testemumha & Comercial & i.a. gramas & Formulado (L ou kg) \\
\hline Testemunha capinada & & & \\
\hline Trifloxysulfuron-sodium + Ametrina & & & \\
\hline Trifloxysulfuron-sodium + Ametrina & Krismat & 720 & 1,50 \\
\hline Mesotrione & Krismat & 960 & 0,00 \\
\hline Mesotrione & Callisto & 182,8 & 0,25 \\
\hline Mesotrione + Ametrine & Callisto & 292,6 & 0,40 \\
\hline Mesotrione + T. sodium & Callisto + Gesapax & $292,6+1.500$ & $0,40+3,00$ \\
\hline Metribuzim & Callisto + Krismat & $182,8+720$ & 4,00 \\
\hline (T. sodium + Ametrine)+(Hexazinone + Diuron) & Krismat + Velaprk & 2.680 & $1,50+1,50$ \\
\hline Amicarbazone & Dinamic & $720+900$ & 0,15 \\
\hline Sulfentrazone + Ametrine & Boral + Gesapax & 75 & $1,40+3,00$ \\
\hline Hexazinone + Diuron & Velpar k & 1.320 & 2,20 \\
\hline (T. sodium + Ametrina ) + Sulfentrazone & Krismat + Boral & $720+700$ & $1,50+1,40$ \\
\hline
\end{tabular}

Nos tratamento trifloxysulfuron-sodium + ametrina (720 e 960 i.a. g) e mesotrione $(182,8$ i.a. g) foi adicionado Agral a $0,2 \% \mathrm{v} / \mathrm{v}$.

Tabela 2 - Propriedades físico-químicas dos herbicidas utilizados no modelo de fugacidade nível I

\begin{tabular}{|c|c|c|c|c|c|c|c|}
\hline \multirow{2}{*}{ Herbicida } & PM & $\mathrm{Sw}$ & PV & $\mathrm{H}$ & \multirow{2}{*}{$\operatorname{logKow}$} & Koc & \multirow{2}{*}{$\begin{array}{l}\mathrm{pKa} \text { ou } \\
\mathrm{pKb}\end{array}$} \\
\hline & $\left(\mathrm{g} \mathrm{mol}^{-1}\right)$ & $\left(\mathrm{mL} \mathrm{g}^{-1}\right)$ & $(\mathrm{Pa})$ & $\left(\mathrm{Pa} \mathrm{m}^{3} \mathrm{~mol}^{-1}\right)$ & & $\left(\mathrm{mL} \mathrm{g}^{-1}\right)$ & \\
\hline Ametrina & 227,3 & $\begin{array}{c}200 \\
\left(20^{\circ} \mathrm{C}\right)\end{array}$ & $\begin{array}{c}3,65 \times 10^{-4} \\
\left(25^{\circ} \mathrm{C}\right)\end{array}$ & $4,1 \times 10^{-4}$ & $\begin{array}{c}2,63 \\
\left(25^{\circ} \mathrm{C}\right)\end{array}$ & 300 & 4,1 \\
\hline Amicarbazone & 241,3 & $\begin{array}{c}4,6 \\
\left(\mathrm{pH}=4-9,20^{\circ} \mathrm{C}\right)\end{array}$ & $\begin{array}{c}3,0 \times 10^{-6} \\
\left(25^{\circ} \mathrm{C}\right)\end{array}$ & $\begin{array}{c}6,8 \times 10^{-8} \\
\left(20^{\circ} \mathrm{C}\right)\end{array}$ & $\begin{array}{c}1,18 \\
(\mathrm{pH}=4)\end{array}$ & $23-37$ & \\
\hline Diuron & 233,1 & $\begin{array}{c}36,4 \\
\left(25^{\circ} \mathrm{C}\right)\end{array}$ & $\begin{array}{l}1,1 \times 10^{-6} \\
\left(25^{\circ} \mathrm{C}\right)\end{array}$ & $7,04 \times 10^{-6}$ & $\begin{array}{c}2,85 \\
\left(25^{\circ} \mathrm{C}\right)\end{array}$ & 400 & \\
\hline Hexazinone & 252,3 & $\begin{array}{c}33 \\
\left(25^{\circ} \mathrm{C}\right)\end{array}$ & $\begin{array}{c}0,03 \times 10^{-3} \\
\left(25^{\circ} \mathrm{C}\right)\end{array}$ & & $\begin{array}{c}1,2 \\
(\mathrm{pH}=7)\end{array}$ & & \\
\hline Mesotrione & 339,3 & $\begin{array}{c}15 \\
\left(20^{\circ} \mathrm{C}\right)\end{array}$ & $\begin{array}{c}5,69 \times 10^{-6} \\
\left(20^{\circ} \mathrm{C}\right)\end{array}$ & $<9,98 \times 10^{-7}$ & & $19-387$ & 3,12 \\
\hline Metribuzin & 214,3 & $\begin{array}{c}1,05 \\
\left(20^{\circ} \mathrm{C}\right)\end{array}$ & $\begin{array}{c}0,058 \times 10^{-3} \\
\left(20^{\circ} \mathrm{C}\right)\end{array}$ & $\begin{array}{c}1,0 \times 10^{-5} \\
\left(20^{\circ} \mathrm{C}\right)\end{array}$ & $\begin{array}{c}1,6 \\
\left(5,6,20^{\circ} \mathrm{C}\right)\end{array}$ & 60 & \\
\hline Sulfentrazone & 387,2 & $\begin{array}{c}0,11 \\
\left(\mathrm{pH}=6,25^{\circ} \mathrm{C}\right)\end{array}$ & $\begin{array}{c}1,3 \times 10^{-7} \\
\left(25^{\circ} \mathrm{C}\right)\end{array}$ & $1,33 \times 10^{-7}$ & 1,48 & 43 & 6,56 \\
\hline $\begin{array}{l}\text { Trifloxysulfuron- } \\
\text { sodium }\end{array}$ & 459,3 & $\begin{array}{c}5.016 \\
\left(\mathrm{pH}=7,25^{\circ} \mathrm{C}\right)\end{array}$ & $\begin{array}{c}<0,01 \times 10^{-3} \\
\left(25^{\circ} \mathrm{C}\right)\end{array}$ & $2,6 \times 10^{-5}$ & $\begin{array}{c}-0,43 \\
\left(\mathrm{pH}=7,25^{\circ} \mathrm{C}\right)\end{array}$ & $29-574$ & $\begin{array}{c}4,76 \\
\left(20^{\circ} \mathrm{C}\right)\end{array}$ \\
\hline
\end{tabular}

Fonte: Tomlin (2000); Rodrigues \& Almeida (2005). 


\section{RESULTADOS E DISCUSSÃO}

Os resultados de eficiência demonstraram que todos os herbicidas isolados ou associados, em todas as doses avaliadas, foram altamente eficientes no controle das principais plantas daninhas presentes, como Digitaria horizontalis, Cenchrus echinatus, Emilia fosbergii e Sida cordifolia (Figura 1). Resultados semelhantes foram obtidos por Negrisoli et al. (2007) com a aplicação de amicarbazone $\left(1.400 \mathrm{~g} \mathrm{ha}^{-1}\right)$ no controle de Brachiaria decumbens, Brachiaria plantaginea e Ipomoea grandifolia quando o herbicida atingiu o solo, mesmo aplicado diretamente ou lixiviado da palha pela chuva.

A comparação da eficiência obtida com as aplicações entre os dois sistemas de aplicação - sobre e sob a palha - não mostrou diferenças, tendo em vista que, para a maioria dos tratamentos e doses avaliados, o controle observado foi total. Assim, pode-se inferir que a cobertura propiciada pela massa vegetal da palha remanescente da colheita da cana crua, estimada em $15 \mathrm{t} \mathrm{ha}^{-1}$, auxiliou sobremaneira o controle das principais plantas daninhas presentes, e, por conseguinte, a eficiência dos herbicidas utilizados no período considerado crítico avaliado no presente trabalho. Assim, do ponto de vista de eficácia, de acordo com essa análise, não fez diferença a aplicação sobre ou sob a palha, já que as primeiras chuvas terão a capacidade de levar esse produto até o solo e, neste, a sua redistribuição na zona de atuação sobre o banco de sementes ou sobre o sistema radicular para ser absorvido pelas plantas daninhas.

Quanto aos resultados da seletividade dos herbicidas avaliados aos 15, 30 e 60 DAT, não foram observados sintomas de fitotoxicidade aparente em nenhum dos tratamentos avaliados (Figura 2). Neste trabalho foram
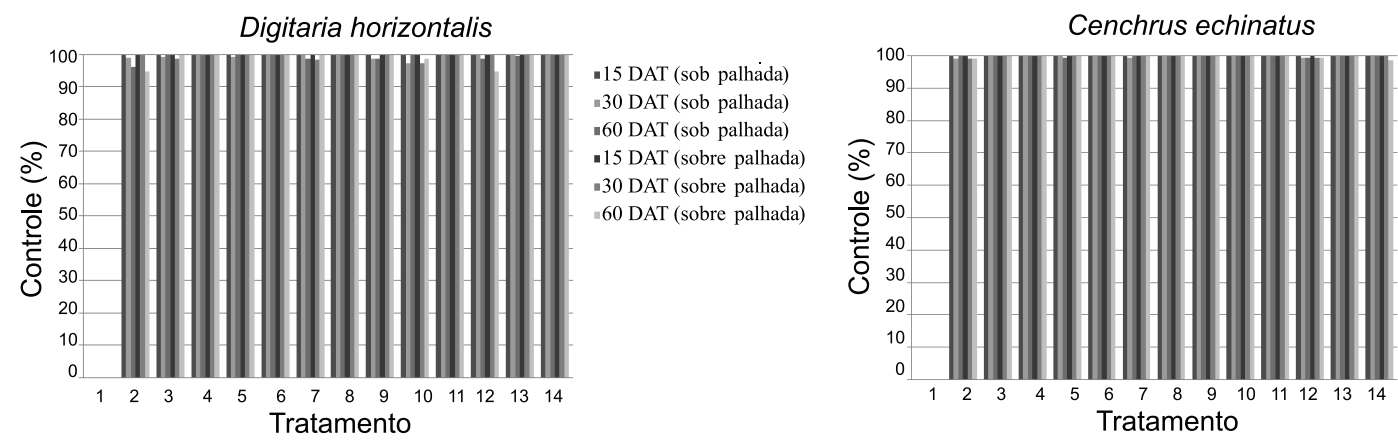

-15 DAT (sob palhada) $=30$ DAT (sob palhada) -60 DAT (sob palhada) -15 DAT (sobre palhada) -30 DAT (sobre palhada) 60 DAT (sobre palhada)
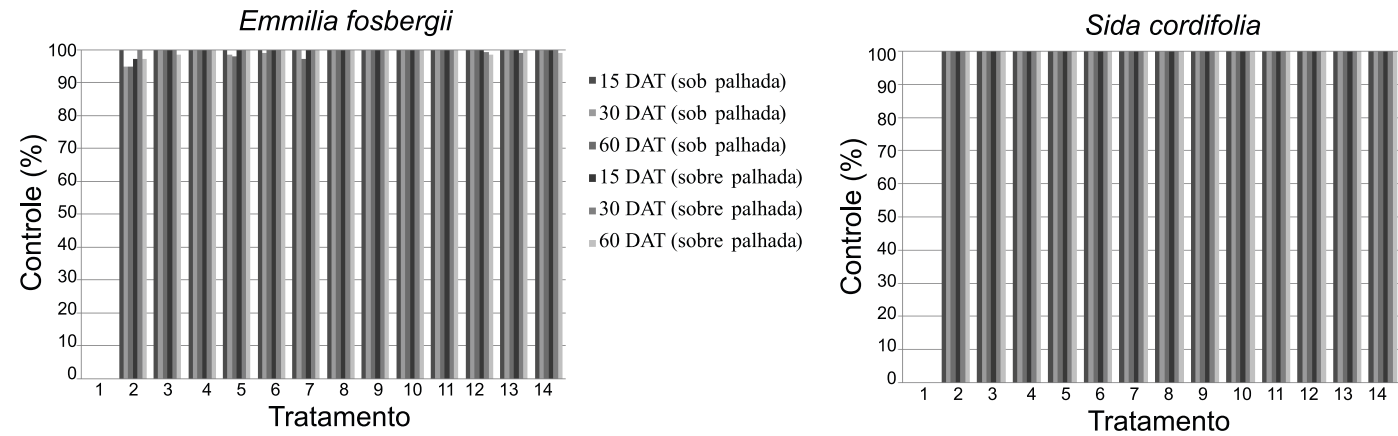

- 15 DAT (sob palhada) - 30 DAT (sob palhada) - 60 DAT (sob palhada) - 15 DAT (sobre palhada) -60 DAT (sob palhada) - 15 DAT (sobre palhada) - 30 DAT (sobre palhada) 60 DAT (sobre palhada)

1 - testemunha; 2 - testemunha capinada; 3 - trifloxysulfuron-sodium + ametrina (720 g i.a.); 4 - trifloxysulfuron-sodium + ametrina (960 g i.a.); 5 - mesotrione (182,6 g i.a.); 6 - mesotrione (292,6 g i.a.); 7 - mesotrione + ametrina $(292,6+1.500) ; 8$ - mesotrione + trifloxysulfuron-sodium $(182,8+720$ g i.a.); 9 - metribuzim $(2.680$ g i.a.); 10 - trifloxysulfuron-sodium + ametrina + hexazinone + diuron $(720+900$ g i.a.); 11 - amicarbazone 45 g i.a.); 12 - sulfentrazone + ametrina (700 g i.a.); 13 - hexazinone + diuron (1.320 g i.a.); 14 - trifloxysulfuron-sodium + ametrina + sulfentrazone $(720+700$ g i.a. $)$.

Figura 1 - Porcentagem de controle (\%) de Digitaria horizontalis, Cenchrus echinatus, Emilia fosbergii e Sida cordifolia aos 15, 30 e 60 dias após a pulverização de herbicidas em pós-emergência sob e sobre a palhada da cana-de-açúcar. 
encontrados resultados distintos de Martini \& Durigan (2004) e Ferreira et al. (2005), que podem ser explicados em função da variedade utilizada em cada trabalho.

Também para os parâmetros altura da última lígula e estande, avaliados aos 60 DAT, não houve diferenças significativas entre os tratamentos avaliados, ou nas diferentes formas de aplicação utilizadas (Figuras 3 e 4). Contudo, quando se estuda a seletividade do herbicida em diferentes doses e variedades de cana, pode haver diferença quanto à redução da altura da planta, do número de folhas, da área foliar e da biomassa da parte aérea e do caule (Ferreira et al., 2005).

Nas Figuras 5 e 6 são apresentados os resultados das avaliações do número de internódios e diâmetro médio do primeiro internódio aos 60 DAT, respectivamente. Em ambos os parâmetros avaliados não foram observadas diferenças significativa entre os tratamentos herbicidas e a forma da sua aplicação, pois as plantas daninhas foram controladas efetivamente em ambas as condições; também não foram observados sintomas de fitotoxicidade aparente sobre e sob a palha.

Com relação ao comportamento ambiental, foram determinados os compartimentos preferenciais para cada herbicida (principio ativo) utilizado. Os diagramas de distribuição dos vários herbicidas pelos vários comportamentos ambientais avaliados, após a aplicação do modelo Mackay (1991), encontram-se representados na Figura 7. Considerando o herbicida trifloxysulfuron-sodium+diuron, observa-se a preferência pelo compartimento água para esses dois princípios. O mesotrione também mostrou preferência pelo compartimento água. A ametrina, um herbicida muito utilizado na cultura da cana, notadamente em mistura com outros produtos, também tem preferência pelo mesmo compartimento. O metribuzin produto largamente utilizado na cultura da soja na década de 1980 e recentemente registrado para uso na cultura da cana - também mostrou preferência por este compartimento. A formulação de hexazinone+diuron mostrou que ambos os ativos também têm preferência pelo compartimento água; amicarbazone, da mesma forma que os herbicidas anteriores, apresentou afinidade em se distribuir no compartimento água. Finalmente, o sulfentrazone também demonstrou a mesma tendência.

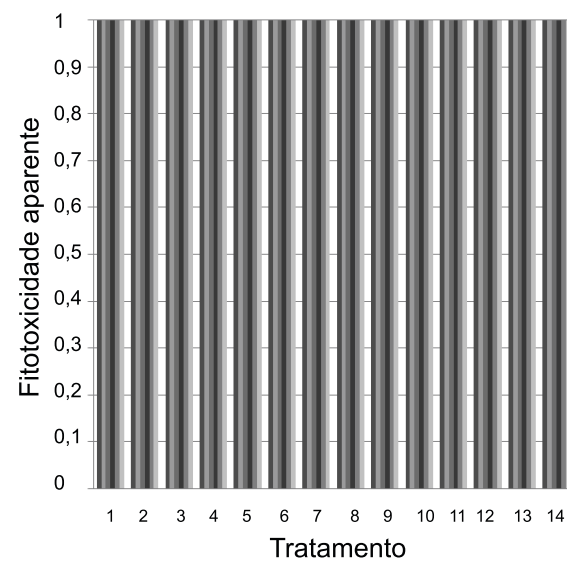

- 15 DAT (sob palhada) - 30 DAT (sob palhada) - 60 DAT (sob palhada) - 15 DAT (sobre palhada) 30 DAT (sobre palhada) $\because 60 \mathrm{DAT}$ (sobre palhada)

1 - testemunha; 2 - testemunha capinada; 3 - trifloxysulfuronsodium + ametrina (720 g i.a.); 4 - trifloxysulfuron-sodium + ametrina (960 g i.a.); 5 - mesotrione (182,6 g i.a.); 6 - mesotrione $(292,6$ g i.a. $) ; 7$ - mesotrione + ametrina $(292,6+1.500) ; 8$ mesotrione + trifloxysulfuron-sodium $(182,8+720$ g i.a. $)$; 9 metribuzim (2.680 g i.a.); 10 - trifloxysulfuron-sodium + ametrina + hexazinone + diuron $(720+900$ g i.a. $) ; 11$ - amicarbazone 45 g i.a.); 12 - sulfentrazone + ametrina (700 g i.a.); 13 hexazinone + diuron (1.320 g i.a.); 14 - trifloxysulfuron-sodium + ametrina + sulfentrazone $(720+700$ g i.a. $)$.

Figura 2 - Avaliação da fitotoxicidade aparente aos 15, 30 e 60 dias após a aplicação de herbicidas em pós-emergência sob e sobre a palhada na cultura da cana-de-açúcar.

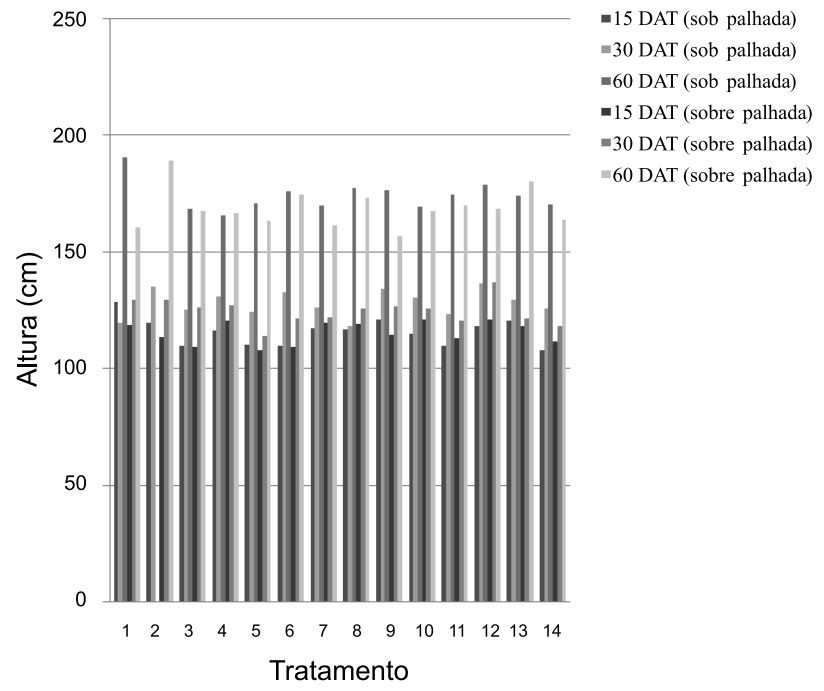

1 - testemunha; 2 - testemunha capinada; 3 - trifloxysulfuronsodium + ametrina (720 g i.a.); 4 - trifloxysulfuron-sodium + ametrina (960 g i.a.); 5 - mesotrione ( $182,6 \mathrm{~g}$ i.a.); 6 - mesotrione $(292,6$ g i.a. $) ; 7$ - mesotrione + ametrina $(292,6+1.500) ; 8$ mesotrione + trifloxysulfuron-sodium $(182,8+720$ g i.a. $) ; 9$ metribuzim ( 2.680 g i.a.); 10 - trifloxysulfuron-sodium + ametrina + hexazinone + diuron $(720+900$ g i.a. $) ; 11$ - amicarbazone 45 g i.a.); 12 - sulfentrazone + ametrina (700 g i.a.); 13 hexazinone + diuron (1.320 g i.a.); 14 - trifloxysulfuron-sodium + ametrina + sulfentrazone $(720+700$ g i.a. $)$

Figura 3 - Avaliação da altura aos 15, 30 e 60 dias após a aplicação de herbicidas em pós-emergência sob e sobre a palhada na cultura da cana-de-açúcar 


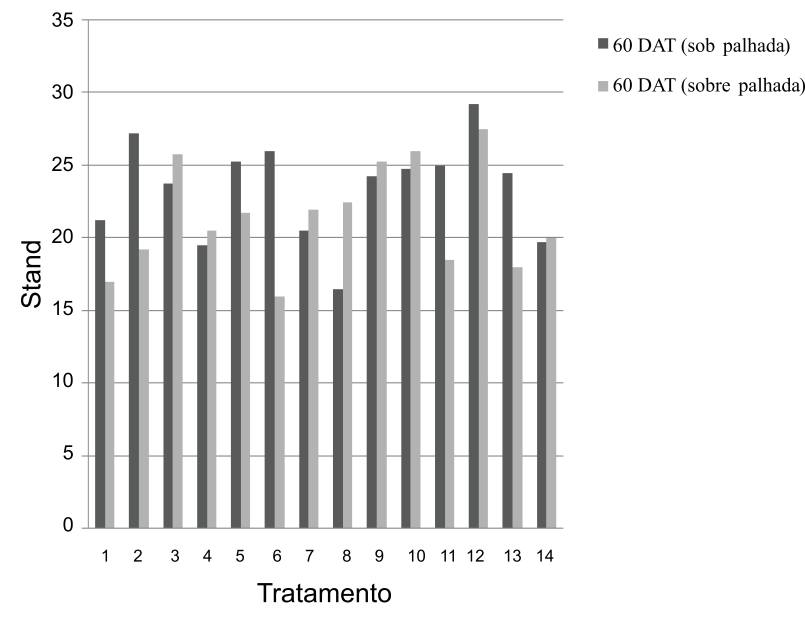

1 - testemunha; 2 - testemunha capinada; 3 - trifloxysulfuronsodium + ametrina (720 g i.a.); 4 - trifloxysulfuron-sodium + ametrina (960 g i.a.); 5 - mesotrione (182,6 g i.a.); 6 - mesotrione $(292,6$ g i.a. $) ; 7$ - mesotrione + ametrina $(292,6+1.500) ; 8$ mesotrione + trifloxysulfuron-sodium $(182,8+720$ g i.a.); 9 metribuzim (2.680 g i.a.); 10 - trifloxysulfuron-sodium + ametrina + hexazinone + diuron $(720+900$ g i.a. $) ; 11$ - amicarbazone 45 g i.a.); 12 - sulfentrazone + ametrina (700 g i.a.); 13 hexazinone + diuron (1.320 g i.a.); 14 - trifloxysulfuron-sodium + ametrina + sulfentrazone $(720+700$ g i.a. $)$

Figura 4 - Avaliação do stand aos 60 dias após a aplicação de herbicidas em pós-emergência sob e sobre a palhada na cultura da cana-de-açúcar.

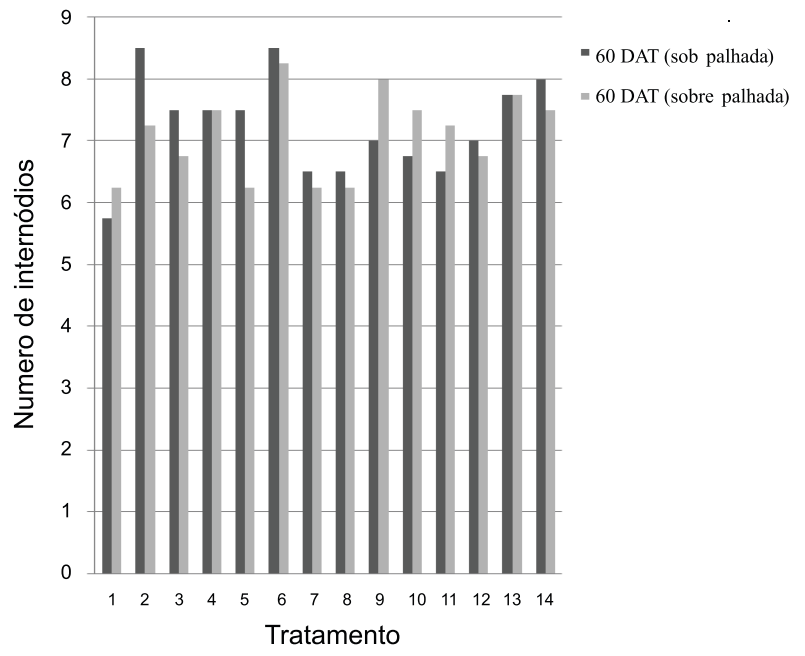

1 - testemunha; 2 - testemunha capinada; 3 - trifloxysulfuronsodium + ametrina (720 g i.a.); 4 - trifloxysulfuron-sodium + ametrina (960 g i.a.); 5 - mesotrione (182,6 g i.a.); 6 - mesotrione $(292,6$ g i.a. $) ; 7$ - mesotrione + ametrina $(292,6+1.500) ; 8$ mesotrione + trifloxysulfuron-sodium $(182,8+720$ g i.a.); 9 metribuzim (2.680 g i.a.); 10 - trifloxysulfuron-sodium + ametrina + hexazinone + diuron $(720+900$ g i.a. $) ; 11$ - amicarbazone 45 g i.a.); 12 - sulfentrazone + ametrina (700 g i.a.); 13 hexazinone + diuron (1.320 g i.a.); 14 - trifloxysulfuron-sodium + ametrina + sulfentrazone $(720+700$ g i.a. $)$

Figura 5 - Avaliação do número de internódios aos 60 dias após aplicação de herbicidas em pós-emergência sob e sobre a palhada na cultura da cana-de-açúcar.

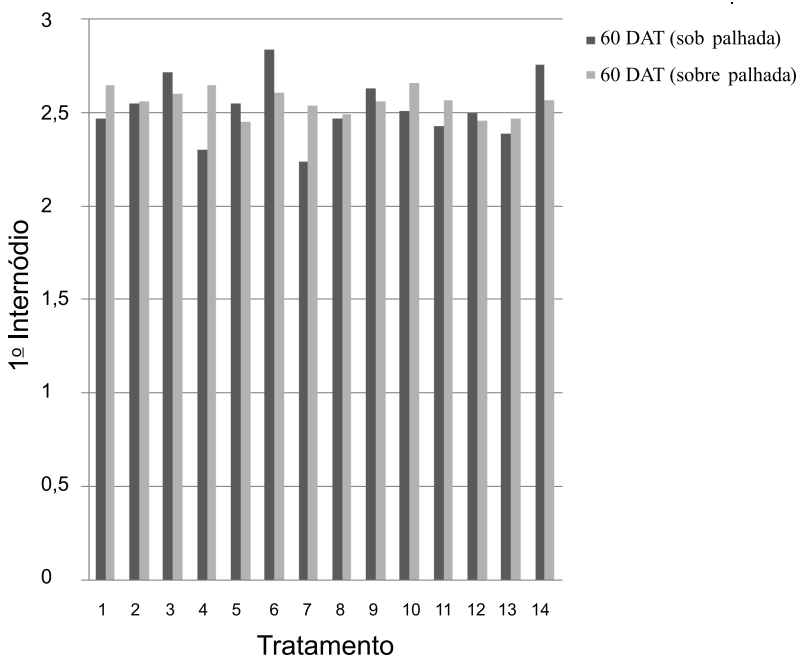

1 - testemunha; 2 - testemunha capinada; 3 - trifloxysulfuronsodium + ametrina (720 g i.a.); 4 - trifloxysulfuron-sodium + ametrina (960 g i.a.); 5 - mesotrione (182,6 g i.a.); 6 - mesotrione $(292,6$ g i.a. $) ; 7$ - mesotrione + ametrina $(292,6+1.500) ; 8$ mesotrione + trifloxysulfuron-sodium $(182,8+720$ g i.a. $) ; 9$ metribuzim ( 2.680 g i.a.); 10 - trifloxysulfuron-sodium + ametrina + hexazinone + diuron $(720+900$ gi.a. $) ; 11$ - amicarbazone 45 g i.a.); 12 - sulfentrazone + ametrina (700 g i.a.); 13 hexazinone + diuron $(1.320$ g i.a. $) ; 14$ - trifloxysulfuron-sodium + ametrina + sulfentrazone $(720+700$ g i.a. $)$.

Figura 6 - Avaliação do 1ํำ internódios aos 60 dias após aplicação de herbicidas em pós-emergência sob e sobre a palhada na cultura da cana-de-açúcar.

De acordo com a tendência dos herbicidas nos diferentes compartimentos avaliados, pelo modelo de fugacidade nivel I (Mackay, 1991), pode-se determinar como preferencial o compartimento água. Este resultado dos herbicidas estudados pode explicar a tendência dos mesmos serem encontrados na solução do solo e atingir o lençol freático, devido ao processo de lixiviação ocasionado pela água da chuva e/ou irrigação. Contudo, isso precisa ser confirmado em situação de campo, a fim de melhor e respaldar o que foi obtido no modelo e no campo sobre o comportamento e destino ambiental desses herbicidas aplicados na área de cana-deaçúcar.

Os resultados obtidos no presente experimento permitem concluir que:

- Os herbicidas trifloxysulfuron+diuron, mesotrione, metribuzin, ametrina, hexazinone+diuron, amicarbazone e sulfentrazone isolados ou associados às taxas utilizadas, aplicados em pós-emergência em área total 

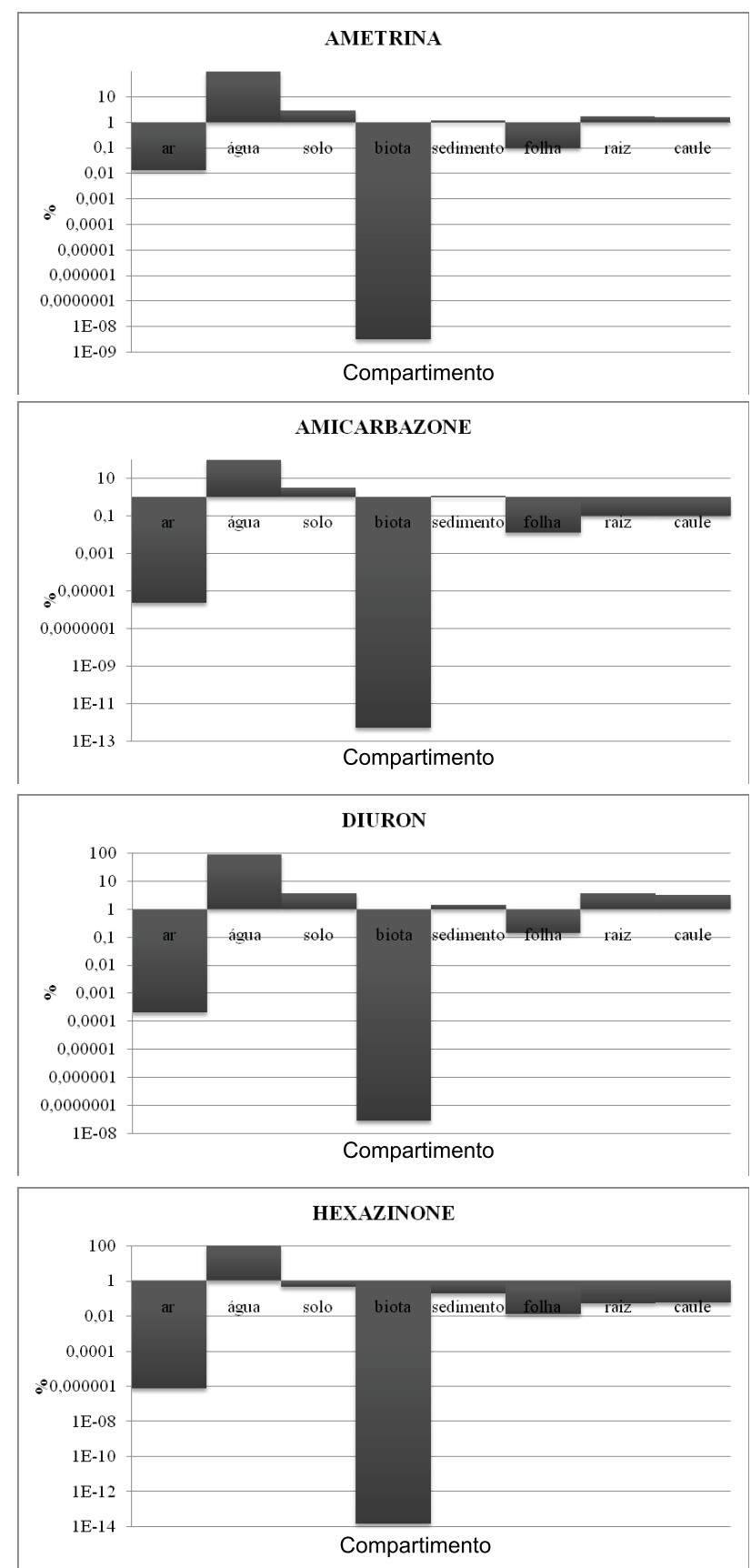
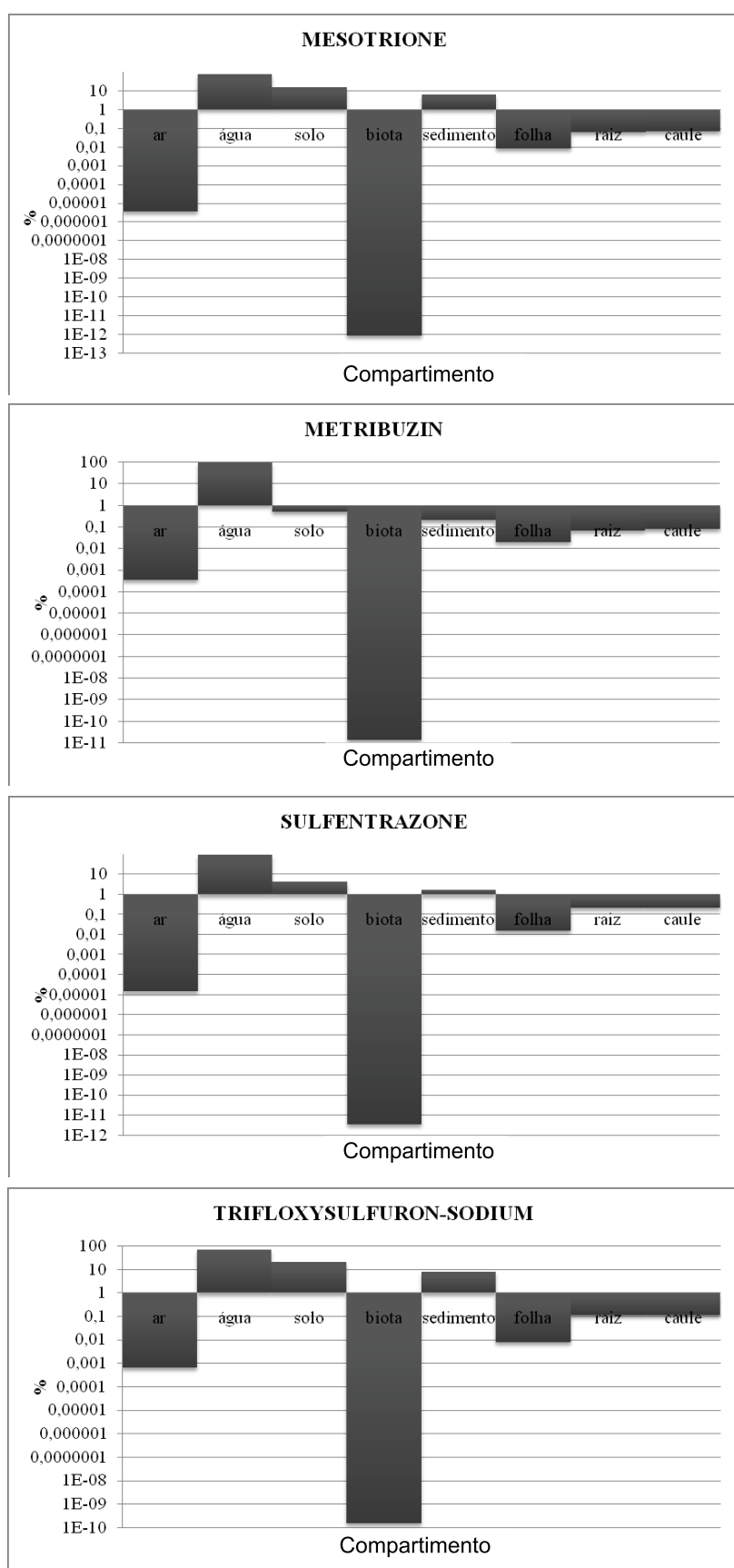

Figura 7 - Diagrama da distribuição dos herbicidas pelos vários compartimentos ambientais estudados na cultura da cana-de-açúcar, aplicando o modelo de fugacidade nível I.

da cultura da cana-de-açúcar, foram altamente eficientes no controle das principais plantas daninhas presentes.

- A aplicação desses herbicidas sobre ou sob a palhada da cana crua não mostrou diferença na eficiência de controle ou sobre os demais parâmetros avaliados.
- A aplicação do modelo de fugacidade mostrou que todos os herbicidas tendem a ter maior distribuição no compartimento água. De modo geral, em função dessa preferência, a aplicação desses produtos não mostrou diferenças nas duas formas aplicadas, sobre ou sob a palhada da cana crua, pois as primeiras chuvas redistribuíram o produto no solo. 


\section{LITERATURA CITADA}

AZANIA, C. A. M. et al. Desenvolvimento da tiririca (Cyperus rotundus) influenciado pela presença ou ausência da palha de cana-de-açúcar e herbicida. Planta Daninha, v. 24, n. 1, p. $29-35,2006$

CALAMARI, D.; VIGHI, M.; BACCI, E. The use of terrestrial plant biomass as a parameter in the fugacity model. Chemosphere, v. 16, n. 10/12, p. 2359-2364, 1987.

CAVENAGHI, A. L. et al. Dinâmica do herbicida amicarbazone (Dinamic) aplicado sobre palha da cana-deaçúcar (Saccarum officinarum). Planta Daninha, v. 25, n. 4, p. 831-837, 2007.

EUROPEAN WEED RESEARCH COUNCIL - EWRC. Report of $3 \mathrm{rd}$ and 4rd meetings of EWRC. Cites of methods in weed research. Weed Res., v. 4, p. 88, 1964.

FERREIRA, E. A. et al. Sensibilidade de cultivares de canade-açúcar à mistura de trifloxysulfuron-sodium + ametryn.

Planta Daninha, v. 23, n. 1, p. 93-99, 2005.

FERREIRA, E. A. et al. Manejo de plantas daninhas em canacrua. Planta Daninha, v.28, n.4, p.915-925, 2010.

MACKAY, D.; PATERSON, S. Calculating fugacity. Environ. Sci. Technol., v. 15, n. 9, p. 1006-1014, 1981

MACKAY, D. Multimedia environmental models the fugacity approach. Chelsea: Lewis Publishers, 1991. $257 \mathrm{p}$.

MARTINI, G.; DURIGAN, J. C. Influência do teor de água na superfície do solo sobre a eficácia e seletividade do flazasulfuron, na cultura da cana-de-açúcar. Planta Daninha, v. 22, n. 2 , p. $259-267,2004$

MONQUERO, P. A. et al. Eficácia de herbicidas em diferentes quantidades de palha de cana-de-açúcar no controle de Euphorbia heterophylla. Planta Daninha, v. 25, n. 3, p. $613-619,2007$

MONQUERO, P. A. et al. Eficácia de herbicidas aplicados em diferentes épocas e espécies daninhas em área de cana-deaçúcar colhida mecanicamente. Planta Daninha, v.27, n.2, p.309-317, 2009a.
MONQUERO, P. A. et al. Eficácia de herbicidas aplicados em diferentes épocas sobre B. pilosa e I. quamoclit em área de cana-de-açúcar colhida mecanicamente. Planta Daninha, v.27, n.3, p.563-570, 2009b.

NEGRISOLI, E. et al. Controle de plantas daninhas pelo amicarbazone aplicado na presença de palha na cana de-açúcar. Planta Daninha, v. 25, n. 3, p. 603-611, 2007a.

NEGRISOLI, E. et al. Associação do herbicida tebuthiuron com a cobertura de palha no controle de plantas daninhas no sistema de cana crua. Planta Daninha, v. 25, n. 3, p. 621-628, $2007 \mathrm{~b}$

PARAÍBA, L. C. et al. Simulation of the fate of the insecticide carbofuran in a rice field using a level IV fugacity model. Spanish J. Agr. Res., v. 5, n. 1, p. 41-50, 2007.

PLESE, L. P. M.; SILVA, C. L.; FOLONI, L. L. Distribuição nos compartimentos ambientais dos herbicidas utilizados nas culturas de algodão, café e citros. Planta Daninha, v. 27, n. 1, p.123-132, 2009

RODRIGUES, B. N.; ALMEIDA, F. S. Guia de herbicidas. 5.ed. Londrina: 2005. $591 \mathrm{p}$.

SILVA, C. L. et al. Previsão ambiental da distribuição dos pesticidas aplicados na cultura do arroz. Pesticidas: $\mathbf{R}$.

Ecotoxicol. Meio Amb., v. 17, p. 75-86, 2007.

SIMONI, F. et al. Eficácia do imazapic e sulfentrazone sobre Cyperus rotundus em diferentes condições de chuva e palha de cana-de-açúcar. Planta Daninha, v. 24, n. 4, p. 769-778, 2006.

SOCIEDADE BRASILEIRA DA CIÊNCIA DAS PLANTAS DANINHAS - SBCPD. Procedimentos para instalação, avaliação e análise de experimentos com herbicidas Londrina: 1995. $42 \mathrm{p}$.

TOLEDO, R. E. B. et al. Eficácia do herbicida amicarbazone aplico sobre a palha ou no solo no controle de plantas daninhas na cultura da cana-de-açúcar. Planta Daninha, v.27, n.2, p.319-326, 2009.

TOMLIN, C. D. S. The pesticide manual. Farnham: British Crop Protection Council, 2000.

VELINI, E. D.; NEGRISOLI, E. Controle de plantas daninhas em cana crua. In: CONGRESSO BRASILEIRO DA CIÊNCIA DAS PLANTAS DANINHAS. Foz do Iguaçu. Palestras... Foz do Iguaçu: SBCPD, 2000. p. 148-164. 